\title{
Metabolic Connection between Incretins and Pulmonary Hypertension
}

Flávio Fontes Pirozzi', Marco Antônio Fernandes Dias ${ }^{2}$, Idiberto José Zotarelli Filho ${ }^{3,4}$, Luiz Gustavo De Quadros ${ }^{3}$, Roberto Luiz Kaiser Júnior ${ }^{3}$, Mário Flamini Júnior ${ }^{3}$, Mikaell Alexandre Gouvea Faria ${ }^{3}$ and Ivan Enokibara da Silva ${ }^{3}$

${ }^{1}$ Division of Endocrinology of Medical School (Unilago) / Sao Jose do Rio Preto, SP, Brazil

${ }^{2}$ Division of Endocrinology of Medical School (FAMERP), Sao Jose do Rio Preto, SP, Brazil

${ }^{3}$ Kaiser Clinic and Hospital, Sao Jose do Rio Preto SP Brazil

${ }^{4}$ State University of Sao Paulo-Ibilce-Unesp, Rua Cristovao Colombo 2265, Sao Jose do Rio Preto SP, Brazil

\begin{abstract}
Studies show that at least half the adult population is overweight in most countries. Recent case reports have shown the important metabolic potential of the pathophysiology of PAH. Many cases of PAH, etiologically classified as idiopathic, present an important interaction with insulin resistance, glucose intolerance and adiponectin deficiency. However, very little of these effects is operated GLP1 link receiver in his lung. About 20 years it is known of the presence of GLP1R lung and also the statement of GLP1 in vasorelaxation of pulmonary artery in animal models but few papers relating this incretin in the pathophysiology and treatment of $\mathrm{PAH}$. The mimic incretins hypoglycemic drugs - the iDPP4 and GLP1a - would have a great therapeutic potential in diabetic patients with PAH. More studies are needed to evaluate the benefit of these medications in the treatment of PAH as well as its effectiveness of these effects in non-diabetic patients.
\end{abstract}

\section{Keywords: T2DM; Pulmonary Arterial Hypertension; DPP4; NO}

\section{Background}

Currently, diabetes and obesity are major metabolic diseases and a major worldwide epidemic. Studies show that at least half the adult population is overweight in most countries. With the increase in obesity is also increasing in prevalence of diseases that comprise metabolic syndrome such as hypertension, dyslipidemia, and type 2 diabetes mellitus (T2DM) [1]. Besides the classic diabetes-related complications such as retinopathy, nephropathy, neuropathy and the atherosclerotic diseases, such as myocardial infarction and stroke [2], other diseases emerge as potential complications of these metabolic changes, including pulmonary arterial hypertension (PAH) [3].

Many cases of PAH, etiologically classified as idiopathic, present an important interaction with insulin resistance $[4,5]$, glucose intolerance [6] and adiponectin deficiency [7-10]. The formation of advanced glycation end products (AGE), increased by chronic hyperglycemia appears to be important in the development of PAH [11,12].

Low HDL-cholesterol levels are associated with worsening of PAH and the use of simvastatin has proved effective in preventing pulmonary fibrosis and improving physical function in patients with PAH $[13,14]$. Recently, it improved PAH was evidenced with decreased systolic right ventricular (SHV), as examination of transthoracic echocardiography in an obese patient with weight loss after undergoing bariatric surgery $[4,15]$.

In the pancreas, the GLP1 receptor (GLP1R) are present on various cells in the human body and, for this reason, there are many pleiotropic effects as a result of the use of iDDP4 and GLP1 analogs (GLP1a) in the heart, kidney, liver, heart, fat, stomach, central nervous system, etc. $[16,17]$.

However, very little of these effects is operated GLP1 link receiver in his lung. About 20 years it is known of the presence of GLP1R lung and also the statement of GLP1 in vasorelaxation of pulmonary artery in animal models but few papers relating this incretin in the pathophysiology and treatment of PAH $[18,19]$. Reduction of the incretin effect in the pathophysiology of T2DM, with decreased production of GLP1 and increase in enzyme activity DDP4 [20], could explain the relationship between the HAP with the metabolic syndrome.

Thus, PAH has characteristic symptoms such as dyspnea, cyanosis, palpitations, persistent coughing, dizziness and syncope that could be related to other diseases and even other complications in an obese and diabetic patient. For this reason, it is important endocrinologists be attentive to the presence of some of these symptoms and suspicion of HAP request an echocardiogram to measure the RVSP or cardiac catheterization of the right chambers, gold standard for diagnosis of the disease [21].

Further, PAH occurs by an imbalance between vasodilator and vasoconstrictor agents, and the reduction of incretins could contribute to the vasoconstriction of the pulmonary artery and the development of PAH. Currently this condition is treated with medications and basic oxygen therapy for the treatment of $\mathrm{PAH}$ as anticoagulants, diuretics, calcium channel blockers, and more specifically phosphodiesterase- 5 inhibitor (sildenafil), prostacyclin analogs, and endothelin receptor inhibitor (bosentan).

In addition to these medications, the mimic incretins hypoglycemic drugs - the iDPP4 and GLP1a - would have a great therapeutic potential in diabetic patients with PAH. More studies are needed to evaluate the benefit of these medications in the treatment of PAH as well as its effectiveness of these effects in non-diabetic patients.

The aim of this study was to evaluate the treatment in patients

${ }^{*}$ Corresponding author: Dr. Flavio Fontes Pirozzi, Disciplina de Endocrinologia da faculdade de medicina da Unilago / Sao Jose do Rio Preto / SP, Brazil, Tel: + 5517-3225-1121; +5517-99713-6049; E-mail: fpirozzi@hotmail.com

Received June 30, 2015; Accepted July 21, 2015; Published July 25, 2015

Citation: Pirozzi F, Fernandes MA, Filho IJZ, Quadros LG, Junior LRK, et al. (2015) Metabolic Connection between Incretins and Pulmonary Hypertension. J Diabetes Metab S13: 014. doi:10.4172/2155-6156.S13-014

Copyright: ( 2015 Pirozzi F, et al. This is an open-access article distributed under the terms of the Creative Commons Attribution License, which permits unrestricted use, distribution, and reproduction in any medium, provided the original author and source are credited. 
with and without diabetic that despite age, reported no episodes of hypoglycemia during the case study.

\section{Methodology}

In the first case, SPLM, patient 63-year-old female with a previous diagnosis of T2DM, obesity, hypertension and dyslipidemia forwarded to endocrine evaluation for better glycemic control and weight loss. $\mathrm{He}$ was wearing only metformin $100 \mathrm{mg}$ day- 1 for glycemic control. In the second case, HFC, patient 74-year-old female with a previous diagnosis of T2DM about three years, obesity, hypertension, dyslipidemia osteopenia, vitamin D deficiency and pulmonary hypertension. Already had echocardiogram with $45 \mathrm{mmHg}$ of SPRV and was followed up with a cardiologist. Because of the risk of hypoglycemia was chosen by the exchange of glyburide by vildagliptin $50 \mathrm{mg}$ twice daily.

\section{Analysis}

In our recent work in 2015, two case reports have shown the important metabolic potential of the pathophysiology of PAH. In the present study, this is the first description in humans that use a iDDP4 (in this case, vildagliptin $50 \mathrm{mg}$ twice daily) may be a treatment option for patients with PAH with T2DM by the presence of GLP1R in the lung. Thus, in the first case there was weight loss and improved glycemic level. In the second case, both the glucose level of the weight remained.

In both cases, using vildagliptin, there was a decrease in systolic pressure of right ventricle pointed out that the relaxation of pulmonary artery has a more beneficial effect would be mediated by NO and activation of vascular potassium channels, further of the effect direct by increasing GLP1, since the IRS1 less inhibited increases the activation of kinases, which in turn increases the stimulus for nitric oxide production in endothelial cells, reducing pulmonary arterial pressure.

Our group showed a reduction of SHV, also through echocardiography in two obese and diabetic patients after starting use of inhibitor of dipeptidyl peptidase (iDDP4) - in this case, vildagliptin $50 \mathrm{mg}$ twice a day- in the treatment of T2DM. Unlike the case that weight loss after bariatric surgery, weight loss in the other two cases who received iDDP4 was insignificant in relation to the patient underwent surgery. As the use of a iDDP4 is capable of increasing the native GLP1, bariatric surgery also promotes the same metabolic disorder.

The interaction of SOCS3 with angiotensin II and with the proteins of the insulin signaling pathways prevents phosphorylation of IRS-1 and IRS-2 tyrosine and serine phosphorylation and activation of AKT (protein kinase). Thus, induction of SOCS3 by angiotensin II prevents the activation of JAK-2 via / STAT-5b by insulin. Therefore, SOCS3 is an interface in insulin signaling systems and angiotensin II.

Thus, insulin resistance, with inhibition of the insulin receptor (IRS1) leads to compensatory hyperinsulinemia and development of endothelial dysfunction, inhibited since the IRS1 prevents the activation of kinases that are involved in generation of the stimulus for the production oxide nitric endothelial cells. Thus, with decreased production of nitric oxide increases the pulmonary arterial pressure [22].

\section{Conclusion}

It was concluded that in the first case there was weight loss and improved glycemic level. In the second case, both the glucose level and the weight remained. In both cases, using vildagliptin, there was a decrease in systolic pressure of right ventricle.

\section{References}

1. Aschner P, Aguilar-Salinas C2, Aguirre L3, Franco L4, Gagliardino JJ5, et al (2014) Diabetes in South and Central America: an update. Diabetes Res Clin Pract 103: 238-243.

2. American Diabetes Association (2014) Standards of medical care in diabetes--2014. Diabetes Care 37 Suppl 1: S14-80.

3. Bogaard HJ, Al Husseini A, Farkas L, Farkas D, Gomez-Arroyo J, et al (2012) Severe pulmonary hypertension: The role of metabolic and endocrine disorders. Pulm Circ 2: 148-154.

4. Zamanian RT, Hansmann G, Snook S, Lilienfeld D, Rappaport KM, et al. (2009) Insulin resistance in pulmonary arterial hypertension. Eur Respir J 33: 318-324.

5. West J, Niswender KD, Johnson JA, Pugh ME, Gleaves L, et al. (2013) A potential role for insulin resistance in experimental pulmonary hypertension. Eur Respir J 41: 861-871.

6. Pugh ME, Robbins IM, Rice TW, West J, Newman JH, et al. (2011) Unrecognized glucose intolerance is common in pulmonary arterial hypertension. J Heart Lung Transplant 30: 904-911.

7. Summer R, Fiack CA, Ikeda Y, Sato K, Dwyer D, et al. (2009) Adiponectin deficiency: a model of pulmonary hypertension associated with pulmonary vascular disease. Am J Physiol Lung Cell Mol Physiol 297: L432-438.

8. Nakagawa Y, Kishida K, Kihara S, Funahashi T, Shimomura I (2009) Adiponectin ameliorates hypoxia-induced pulmonary arterial remodeling. Biochem Biophys Res Commun 382: 183-188.

9. Hansmann G, Rabinovitch M (2010) The protective role of adiponectin in pulmonary vascular disease. Am J Physiol Lung Cell Mol Physiol 298: L1-2.

10. Summer R, Walsh K, Medoff BD (2011) Obesity and pulmonary arterial hypertension: Is adiponectin the molecular link between these conditions? Pulm Circ 1: 440-447.

11. Brownlee M (2005) The pathobiology of diabetic complications: a unifying mechanism. Diabetes 54: 1615-1625.

12. Meloche J, Courchesne A, Barrier M, Carter S, Bisserier M, et al. (2013) Critical role for the advanced glycation end-products receptor in pulmonary arterial hypertension etiology. J Am Heart Assoc 2: e005157.

13. Heresi GA, Aytekin M, Newman J, DiDonato J, Dweik RA (2010) Plasma levels of high-density lipoprotein cholesterol and outcomes in pulmonary arteria hypertension. Am J Respir Crit Care Med 182: 661-668.

14. Schroll S, Lange TJ, Arzt M, Sebah D, Nowrotek A, et al. (2013) Effects of simvastatin on pulmonary fibrosis, pulmonary hypertension and exercise capacity in bleomycin-treated rats. Acta Physiol (Oxf) 208: 191-201.

15. Pugh ME, Newman JH, Williams DB, Brittain E, Robbins IM, et al. (2013) Hemodynamic improvement of pulmonary arterial hypertension after bariatric surgery: a potencial role for metabolic regulation. Diabetes Care 36: e32-e33.

16. Dixon JB, le Roux CW, Rubino F, Zimmet P (2012) Bariatric surgery for type 2 diabetes. Lancet 379: 2300-2311.

17. Gupta V (2012) Pleiotropic effects of incretinics. Indian Journal of Endocrinology and Metabolism 16: S47-S56.

18. Richter G, Feddersen O, Wagner U, Barth P, Göke R, et al. (1993) GLP-1 stimulates secretion of macromolecules from airways and relaxes pulmonary artery. Am J Physiol 265: L374-381.

19. Golpon HA, Puechner A, Welte T, Wichert PV, Feddersen CO (2001) Vasorelaxant effect of glucagon-like peptide-(7-36)amide and amylin on the pulmonary circulation of the rat. Regul Pept 102: 81-86.

20. Fadini GP, Albiero M, Menegazzo L, de Kreutzenberg SV, Avogaro A (2012) The increased dipeptidyl peptidase- 4 activity is not counteracted by optimized glucose control in type 2 diabetes, but is lower in metformin-treated patients. Diabetes Obes Metab 14: 518-522.

21. Galie N, Hoeper MM, Humbert M, Torbicki A, Vachiery JL, et al. (2009) Guideline for the diagnosis and treatment of pulmonary hypertension: the task force for the diagnosis and treatment of pulmonary hypertension of the European Society of Cardiology (ESC) and European Respiratory Society (ERS), endorsed by the International Society of the Heart and Lung Transplantation (ISHLT). European Heart Journal 30: 2493-2537.

22. Fraga PL, Martini-Santos BJ, Severino BNS, Oliveira BRS, França GR (2012) The interface between the type 2 diabetes mellitus and systemic arterial hypertension: biochemical aspects. Cadernos UniFOA, edição n0 20. 